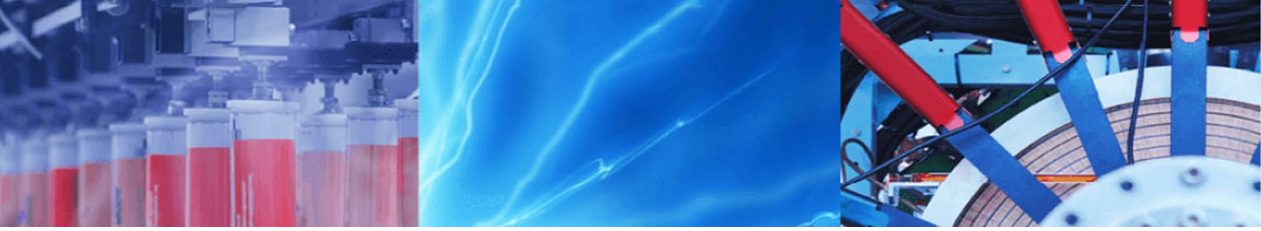

Review Paper

\title{
The effect of different surface topographies of titanium implants on bacterial biofilm: a systematic review
}

\author{
Jagjit Singh Dhaliwal ${ }^{1}$ (D) Nurul Adhwa Rahman ${ }^{1}$. Joe Knights ${ }^{1} \cdot$ Hazim Ghani ${ }^{1}$ • \\ Rubens Ferreira de Albuquerque Junior ${ }^{2}$
}

(c) Springer Nature Switzerland AG 2019

\begin{abstract}
To compare the different surface topographies of titanium implants used in dentistry against the formation of bacterial biofilm. To identify relevant studies, the electronic databases PubMed, Science Direct and Springer Link were searched from inception until January 2019. A total of 38 studies were selected for the systematic review $(n=38)$. The most commonly used titanium surfaces were machined titanium (16.3\%), sandblasted, large-grit, acid-etched titanium (10.9\%), untreated or pure titanium (10.9\%), polished titanium (9.8\%), physically textured titanium (9.8\%), acid-etched titanium $(8.7 \%)$ and anodized titanium (5.4\%). The majority of the studies (78.9\%) found that surface topographies (with varying degrees of roughness) had a beneficial effect on the ability to allow low bacterial biofilm on the surfaces. A low roughness value $\left(R_{a}\right)$ of below $1 \mu \mathrm{m}$ was found in $68 \%$ of these surfaces. Overall, no specific surface topography was found to be the ideal surface in allowing the least bacterial biofilm attachment. In this study, meta-analysis was not performed. This narrative systematic review provides a summary of the effects of surface topographies for future research and development of new dental implant surfaces and decontamination techniques.
\end{abstract}

Keywords Titanium · Dental implant · Biofilm · Bacteria · Surface topography · Profilometry · Systematic review · Dental materials · Periimplantitis

\section{Introduction}

Peri-implantitis is a microbial biofilm-induced inflammatory process which results in the loss of supporting bone around an osseointegrated dental implant [38]. Approximately one-third of patients with dental implants and onefifth of all dental implants experienced peri-implantitis [31]. Patients with bleeding on gentle probing (BOP) had a $33.8 \%$ probability to be diagnosed with peri-implantitis [25]. The reported prevalence of peri-implantitis ranged between 0 and $39.7 \%$ within 5 years from the insertion of the dental implant [17]. One study looked at peri-implantitis prevalence at different levels of the implant, finding a range of $1.1-85.0 \%$ [20]. The same study reported the incidence of periimplantitis from $0.4 \%$ within 3 years to $43.9 \%$ within 5 years [20].

Currently, there is no strong evidence to suggest the most effective treatment for peri-implantitis [48]. Surface topographic features may significantly modify the ability of the titanium surfaces to allow the attachment of bacterial biofilm, hence implying that the roughness of the surfaces were highly correlated with bacterial adhesion [2]. With regards to this, numerous innovative topographic surfaces have been developed and reported in the scientific literature and international patents to prevent the development of microbial biofilm [45-47]. A hypothesis was developed that certain surface topography can provide a surface with minimal bacterial biofilm. Therefore,

$\bowtie$ Jagjit Singh Dhaliwal, jagjit.dhaliwal@ubd.edu.bn | ${ }^{1}$ Pengiran Anak Puteri Rashidah Sa'adatul Bolkiah Institute of Health Sciences, Universiti Brunei Darussalam, Jalan Tungku Link, Gadong, Brunei Darussalam. ${ }^{2}$ Departamento de Materiais Dentários e Prótese, Faculdade de Odontologia de Ribeirão Preto, Universidade de São Paulo, São Paulo, Brazil.

SN Applied Sciences (2019) 1:615 | https://doi.org/10.1007/s42452-019-0638-6

Received: 15 April 2019 / Accepted: 17 May 2019 / Published online: 21 May 2019 
this review focused on the surface topography of the dental implant, highlighting the importance of combating dental implant failures caused by peri-implantitis.

The arithmetical mean roughness $\left(R_{a}\right)$ is used as a parameter to describe the implant surface roughness, which can be measured via stylus profilometry [52]. Differences in surface roughness are sensitive to the different sizes and external membrane compositions of bacterial, mammalian or eukaryotic contaminants [39]. An $R_{a}$ value of less than or equal to $0.088 \mu \mathrm{m}$ can strongly inhibit bacterial adherence during early biofilm formation [40]. However, an $R_{a}$ value of $0.2 \mu \mathrm{m}$ has been widely suggested as a threshold surface roughness under which any further surface smoothing (i.e. lowering of the $R_{a}$ value) did not have an impact on the sub- and supra-mucosal microbial composition [7]. This was based on the idea that an increase in the surface roughness and the surface free energy is equal to an increase in the biofilm formation [19]. A high roughness not only provides a large surface area for bacterial adhesion and additional niches, but also reduces shearing forces and therefore, assists bacteria to escape from the host defense mechanisms during the initial adhesion phase [1]. However, a recent study has shown that an $R_{a}$ value of $0.2 \mu \mathrm{m}$ could not properly predict biofilm formation and did not encourage osseointegration [21]. Therefore, a moderate $R_{a}$ value of 1-2 $\mu$ m was suggested as a pre-requisite for the long-term success of implantsupported prostheses [10]. Various methods have been developed to create a moderately rough surface and to promote the osseointegration of implants, such as plasmaspraying, blasting with ceramic particles, acid-etching and anodization using specific instruments and chemical treatments [28].

This systematic review aimed to compare the bacterial biofilm on the different types of dental titanium implant surfaces reported in the literature.

\section{Method}

A systematic search of the English-language literature indexed in PubMed, Science Direct and Springer Link was conducted from their respective inception up to 1 January 2019. The studies had to be published in English language. The search terms used were "dental" AND "implant" AND "titanium" AND "bacteria" AND "biofilm" AND "treatment" OR "decontamination" OR "eradication" OR "cleaning" OR "remove". Wildcards such as an asterisk (*), a question mark (?), or other designated symbols of each selected database were applied. Original research papers (i.e. experimental studies) that applied titanium-based materials for dental studies were selected for this review. The studies had to report the existence of microbial biofilm and focused on the different types of dental implant surface topographies. Biofilm by both bacteria and fungi were included. The data was extracted and entered into a structured data extraction form using Microsoft Excel facilitating data summarization and the writing of the final report. Data analysis was performed using SPSS Software Version 23 (IBM Corp) and PRISM Software Version 7 (GraphPad Inc.).

\section{Results}

\subsection{Search results}

The electronic search yielded four hundred results from three databases ( $n=400$, Fig. 1). After removing duplicates and further screening, thirty-eight studies were included in this review ( $n=38$, Table 1$)$. These 38 studies specifically focused on the surface topography profiles and modifications of titanium materials, and compared against the amount of bacterial biofilm attachment on the surfaces.
Fig. 1 Flowchart of the study selection process

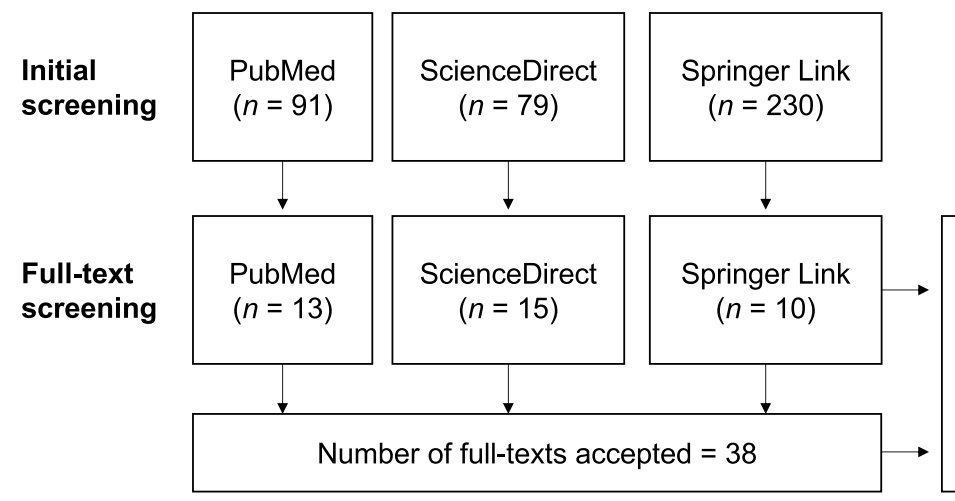

Reasons for rejection

Not original research papers Review papers Non-English papers Duplicate studies No titanium materials No dental focus No microbial biofilm Not about surface topographies No biofilm on the titanium surfaces 


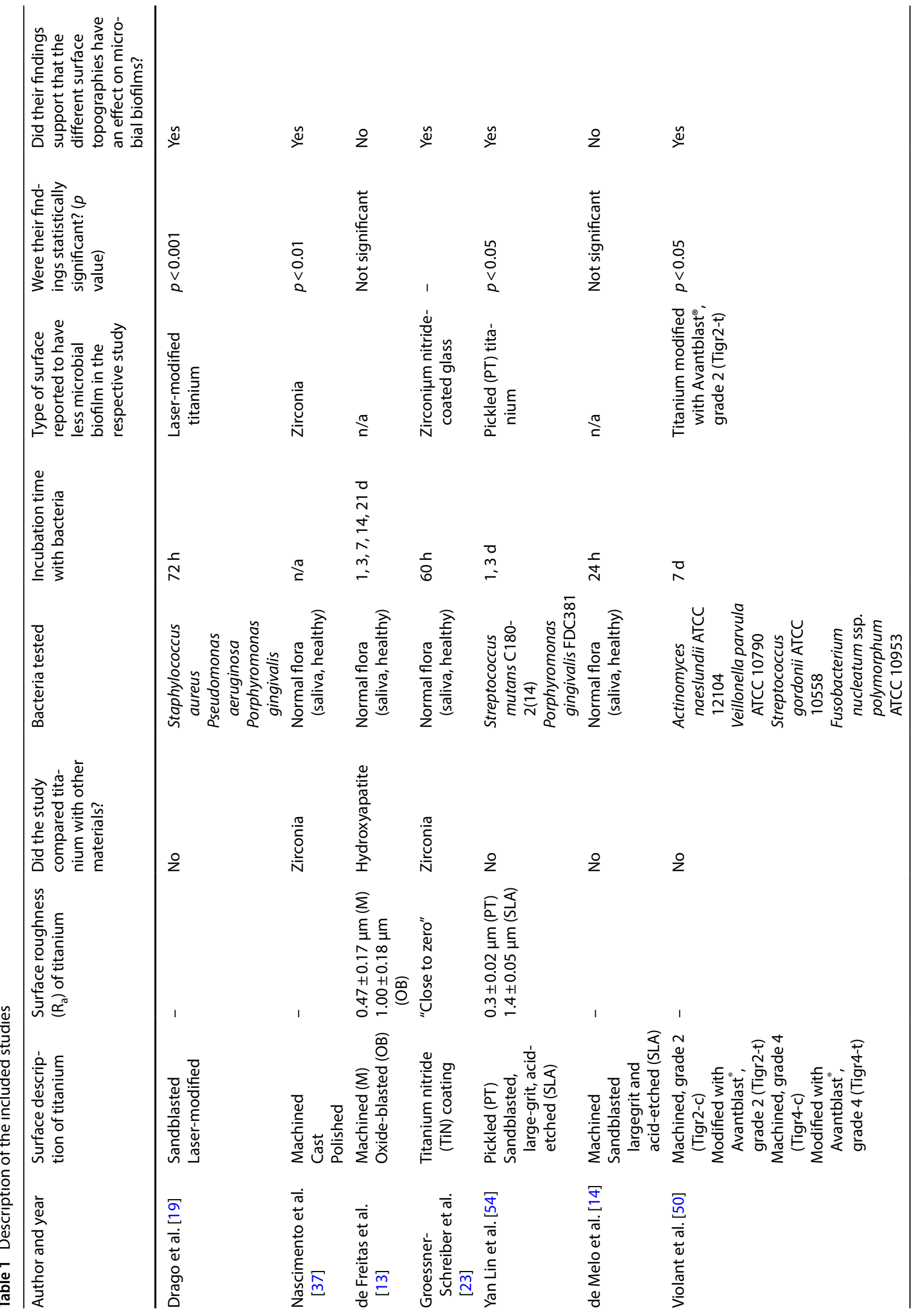




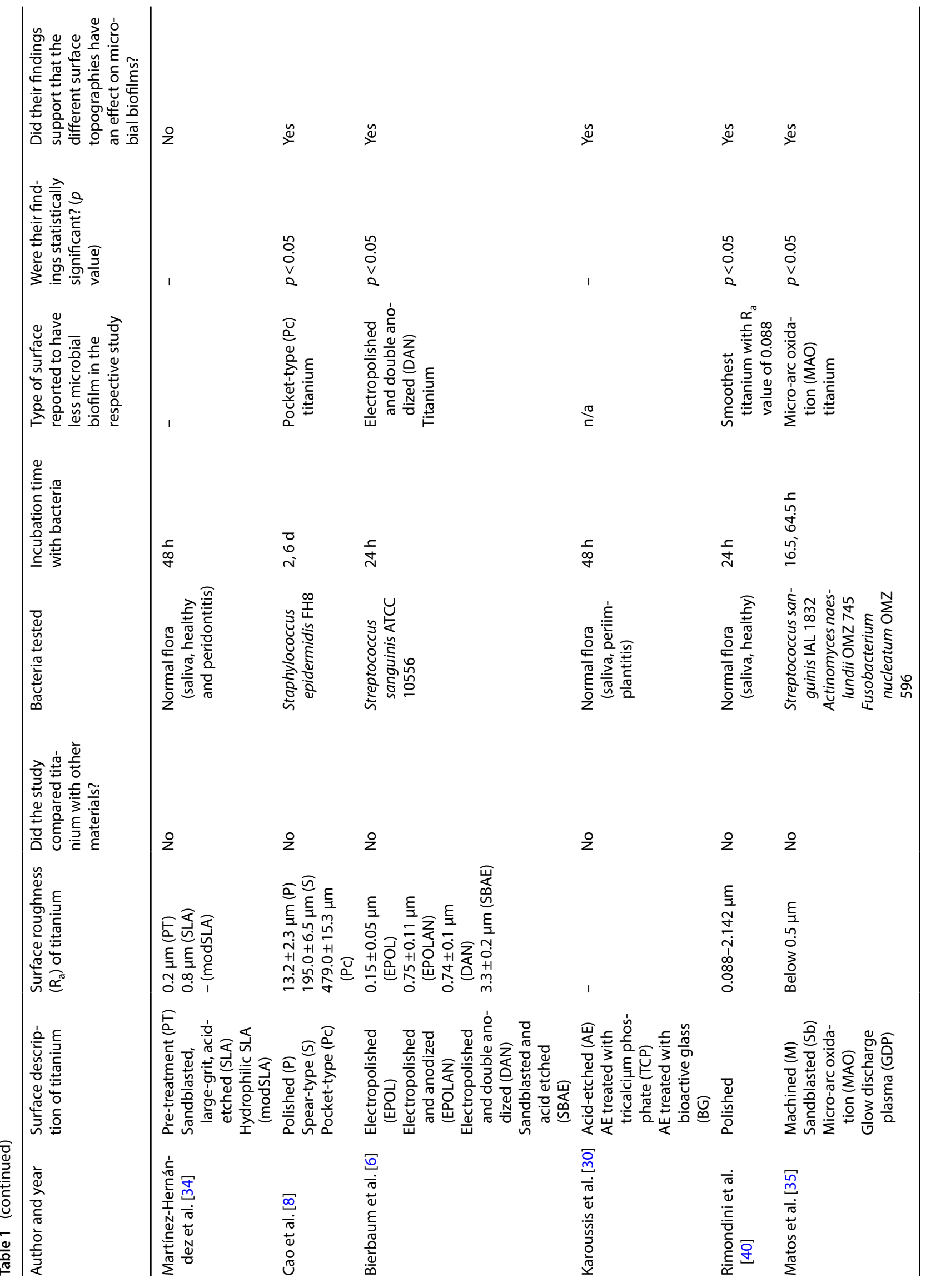




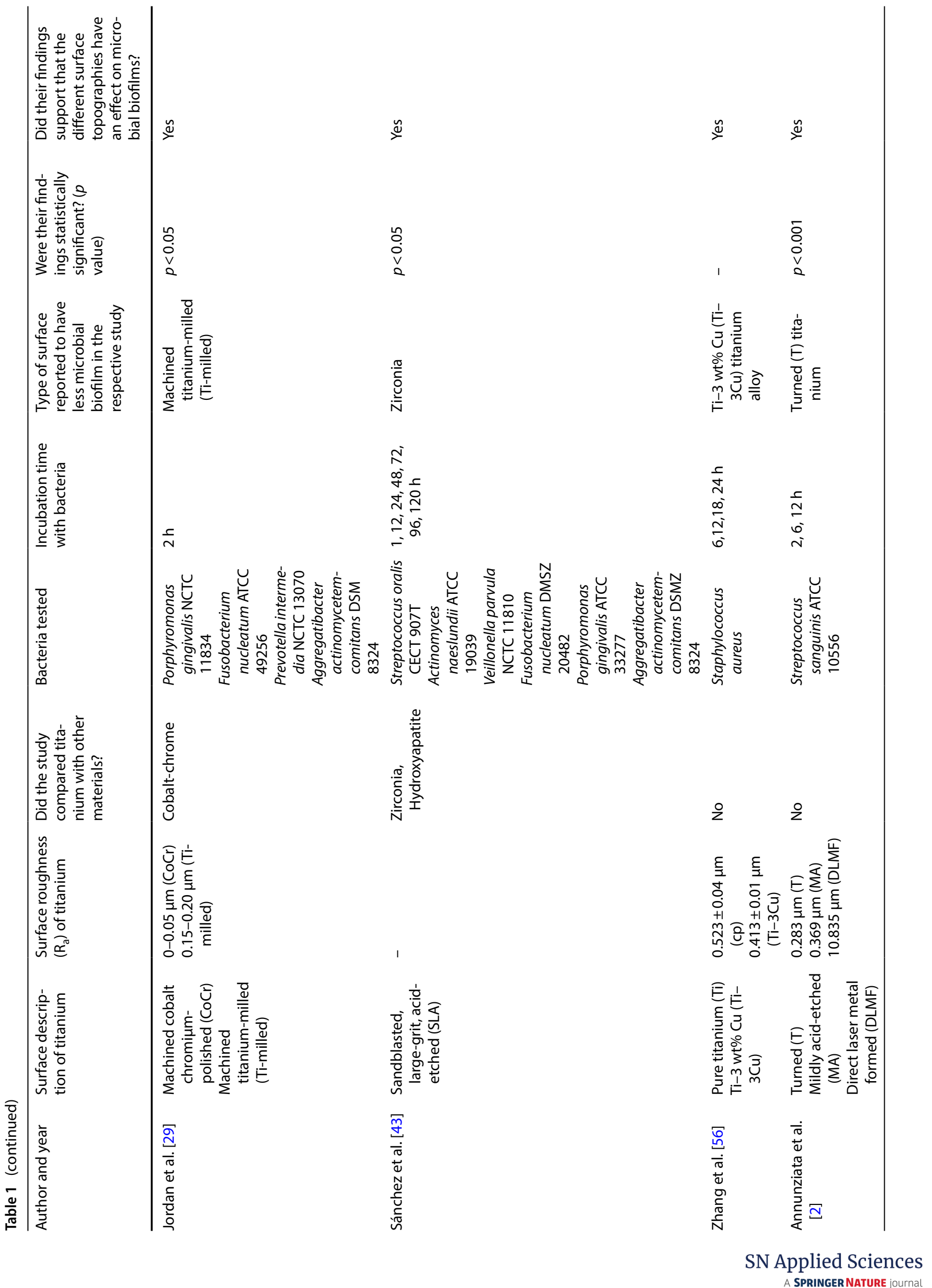




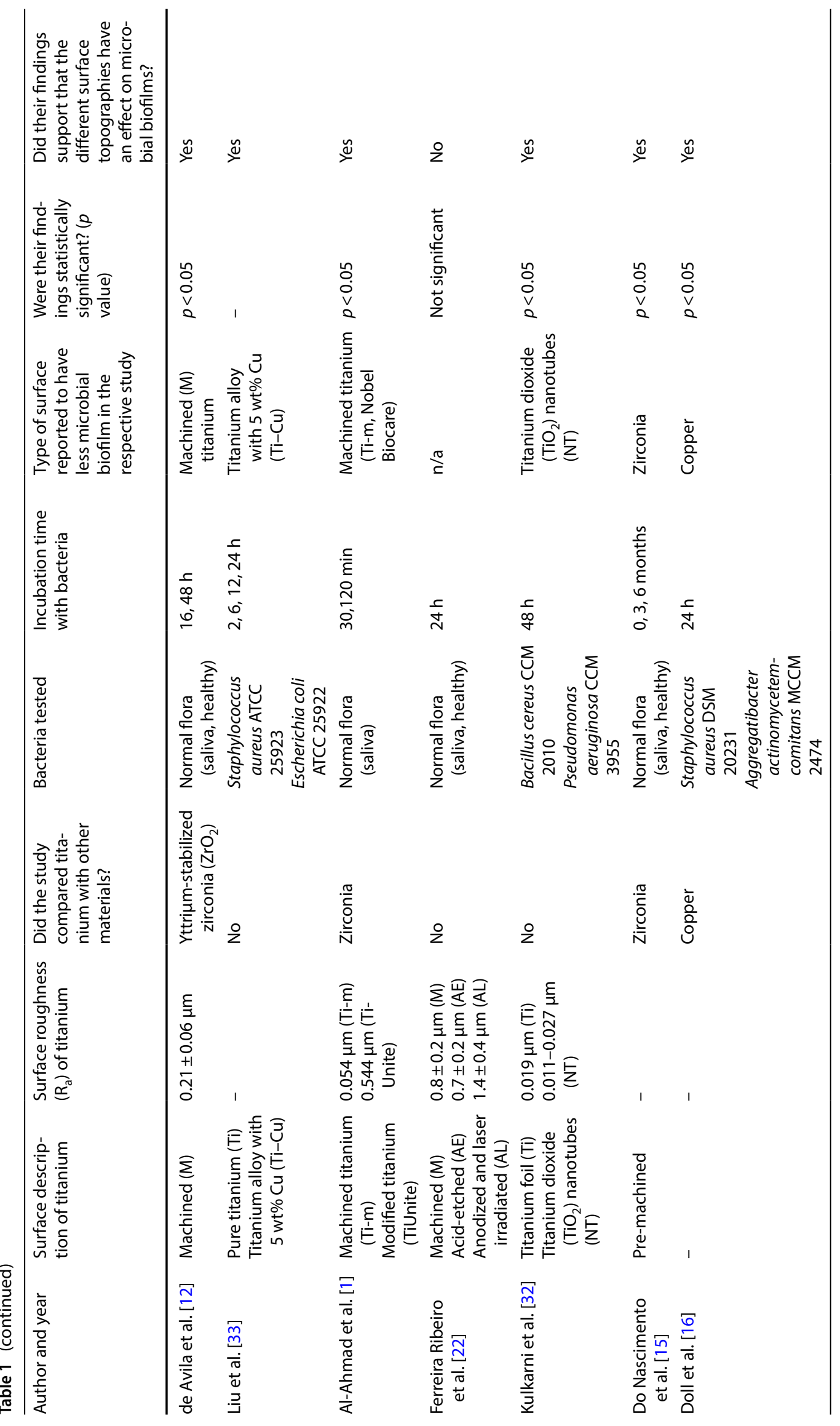




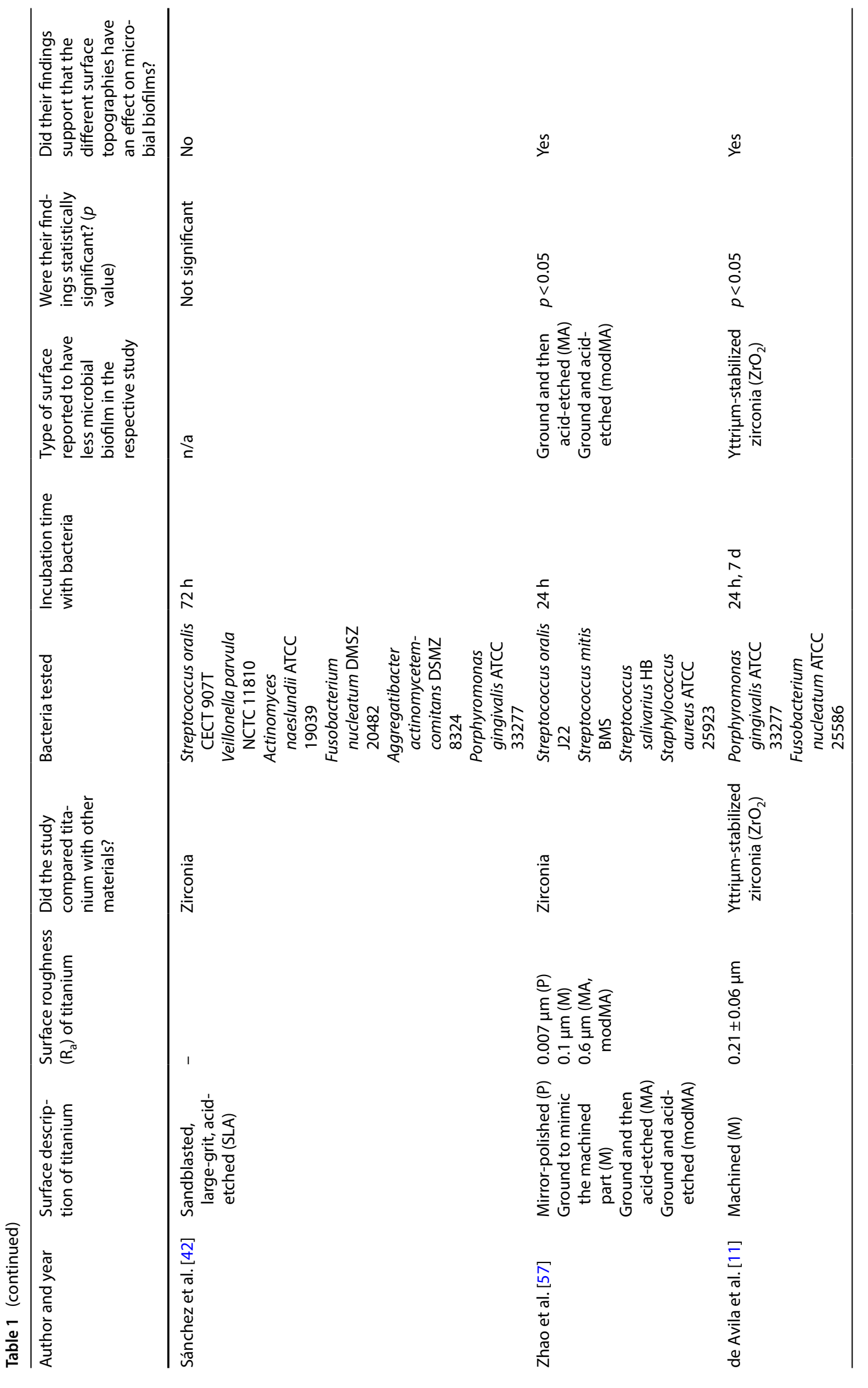




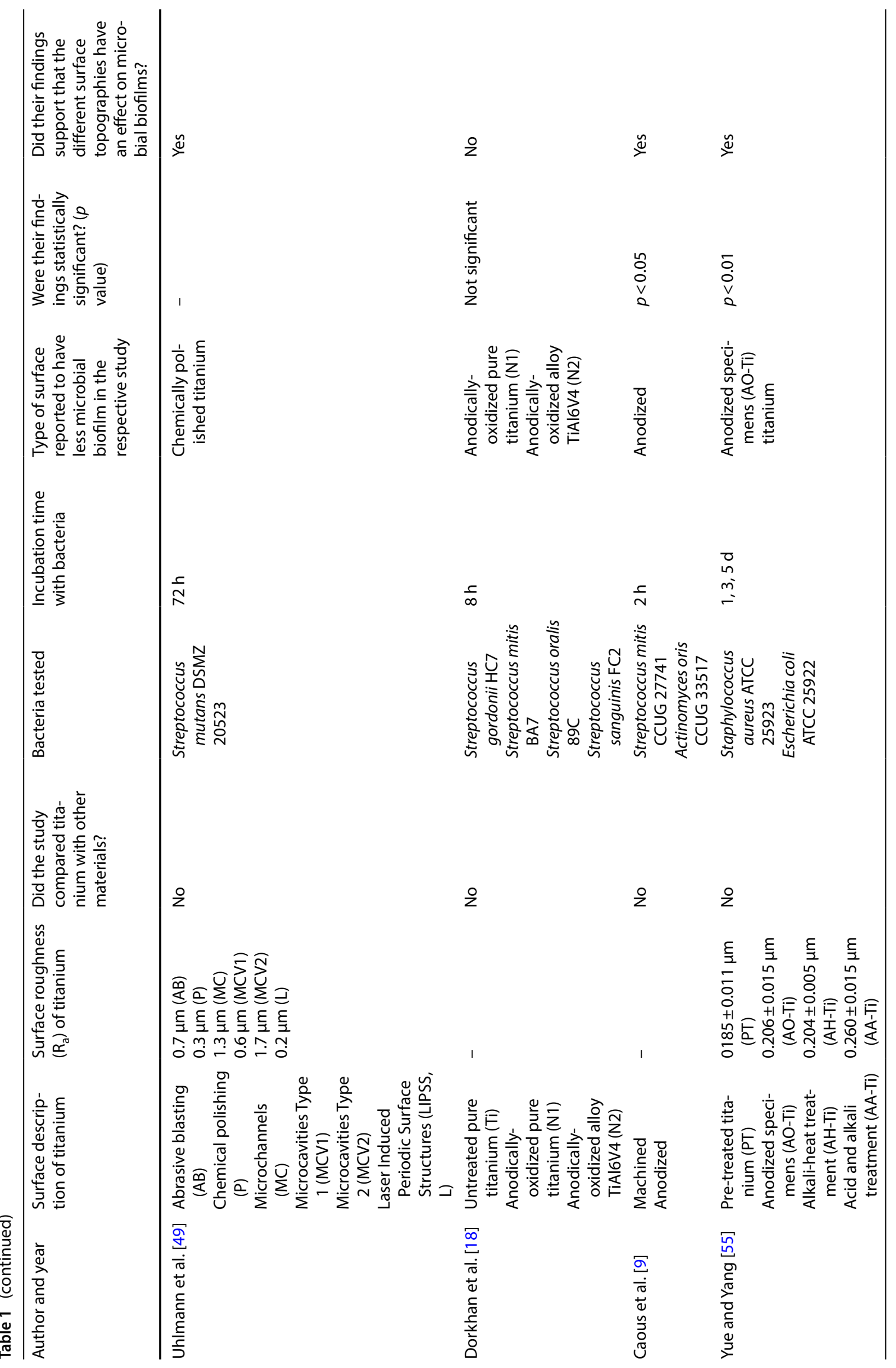

SN Applied Sciences 


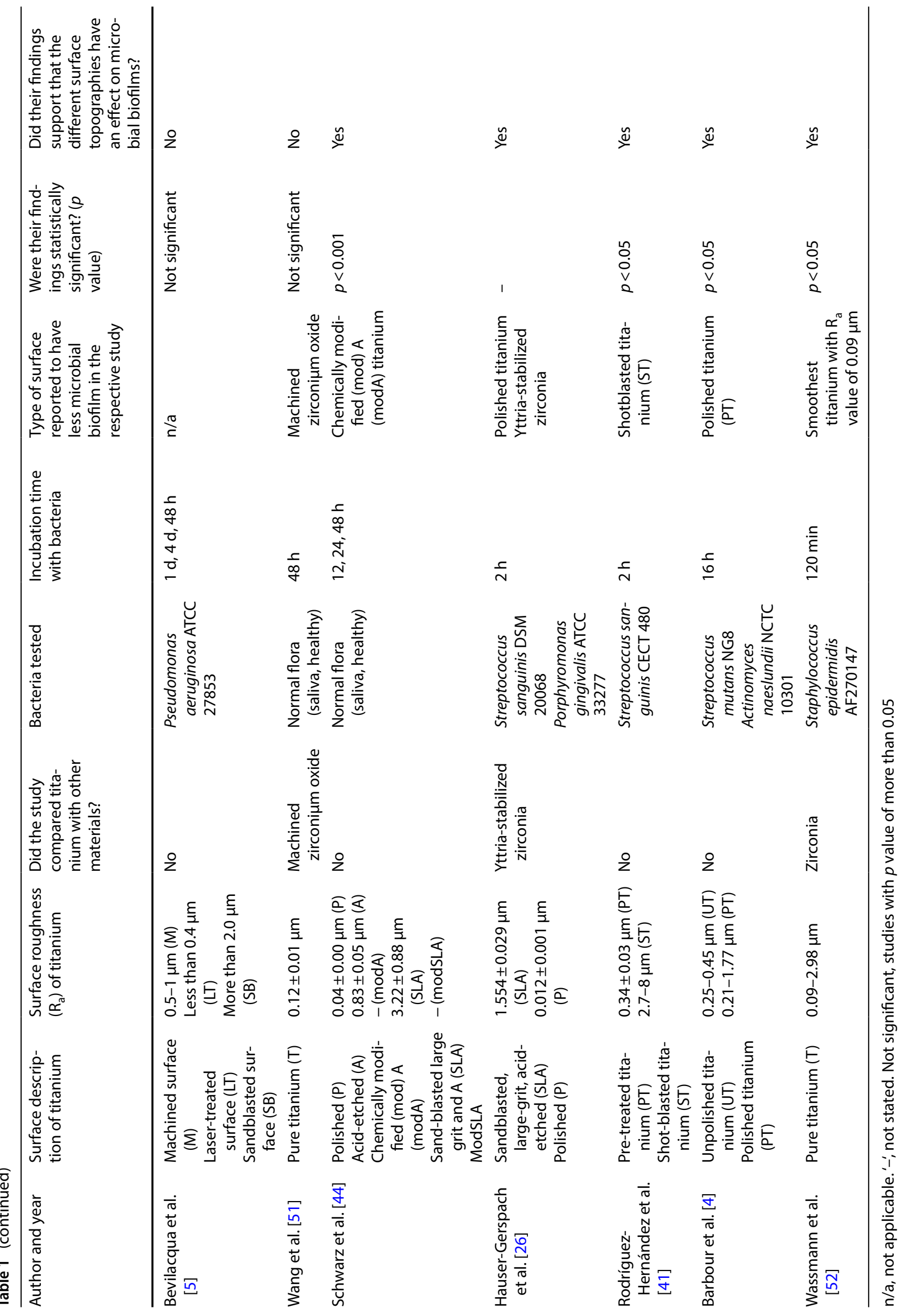




\subsection{Types of titanium implant surfaces}

In this review, the common types of titanium surfaces being investigated were machined titanium, sandblasted, large-grit, acid-etched titanium (SLA), untreated and pure titanium, polished titanium, physically textured titanium, anodized titanium and laser-modified titanium (Table 2). The machined surfaces had a pattern of unidirectional grooves and showed anisotropic irregularities [57]. The SLA titanium surfaces also had an irregular surface [19], which were found to contain voids and open spaces at the surface [57]. The irregularities of an SLA surface can also be reduced by exposure to nitrogen gas [34]. The untreated and pure titanium were not modified and usually included in the investigations as a control. The polished titanium had a flat surface without evident texture and served as the smoothest surface, regardless of its $R_{a}$ value, when compared to machined and SLA [8]. Physically textured titanium represented the surfaces with nanostructures comprising thin spears and uniform nanotubular structures [8, 32]. The anodized titanium surfaces had a bonelike apatite formation on its surface and a rough homogenous and isotropic structure $[9,55]$. The laser-modified surfaces had a controlled geometry consisting of micrometrical holes symmetrical in dimension, shape and distribution [19].

One of the studies also compared the difference between Grade 2 and Grade 4 titanium as these grades have slight differences in their chemical composition [50] (Table 2). Grade 2 titanium has a content of $0.1 \%$ carbon (C), $0.3 \%$ iron $(\mathrm{Fe}), 0.015 \%$ hydrogen $(\mathrm{H}), 0.03 \%$ nitrogen (N), $0.25 \%$ oxygen $(\mathrm{O})$ and $99.2 \%$ titanium (Ti), whereas grade 4 titanium has $0.08 \% \mathrm{C}, 0.5 \% \mathrm{Fe}, 0.015 \% \mathrm{H}, 0.05 \%$ $\mathrm{N}, 0.40 \% \mathrm{O}$ and $98.9 \% \mathrm{Ti}$ [24]. These slight chemical differences between titanium purities could have an important effect on surface properties when titanium was treated with different chemical or physical processes, and therefore, also cause an impact on the early bacterial

Table 2 Characteristics of the included studies

\begin{tabular}{|c|c|c|}
\hline Variable & Frequency (\%) & References \\
\hline \multicolumn{3}{|l|}{ Physical structure of titanium } \\
\hline Discs & $30(78.9)$ & {$[2,5,6,8,9,11,14,16,18,19,22,23,26,29,30,32,34,35,37,40-42,49,50,52,54-57]$} \\
\hline Not discs & $8(21.1 \%)$ & {$[1,4,12,13,15,32,44,51]$} \\
\hline Not stated & $1(2.6 \%)$ & [33] \\
\hline \multicolumn{3}{|l|}{ Nature of experiment } \\
\hline In-vitro & $27(71.1 \%)$ & {$[2,4-6,8,9,11,12,16,18,19,26,29,30,32,33,35,41,42,49,50,52,54-57]$} \\
\hline In-vivo & $14(36.8 \%)$ & {$[1,2,5,13-15,22,23,33,34,37,40,44,51]$} \\
\hline \multicolumn{3}{|l|}{ Types of titanium surfaces } \\
\hline Machined titanium & $15(16.3 \%)$ & {$[1,5,9,11-14,22,29,35,37,50,57]$} \\
\hline $\begin{array}{l}\text { Sandblasted, large-grit, acid- } \\
\text { etched titanium }\end{array}$ & $10(10.9 \%)$ & {$[6,14,26,34,42,44,54]$} \\
\hline Untreated/pure titanium & $10(10.9 \%)$ & {$[4,15,18,33,34,41,51,52,55,56]$} \\
\hline Polished titanium & $9(9.8 \%)$ & {$[4,6,8,26,37,40,44,49,57]$} \\
\hline Physically textured titanium & $9(9.8 \%)$ & {$[1,2,8,32,49,54]$} \\
\hline Acid-etched titanium & $8(8.7 \%)$ & {$[2,22,30,44,57]$} \\
\hline Anodized titanium & $5(5.4 \%)$ & {$[9,18,22,55]$} \\
\hline Laser-modified titanium & $3(3.3 \%)$ & {$[2,5,19]$} \\
\hline Other titanium surfaces & $22(24.2 \%)$ & {$[5,6,13,19,23,32,33,35,37,41,44,49,50,55,56]$} \\
\hline Not stated & $1(1.1 \%)$ & [16] \\
\hline \multicolumn{3}{|l|}{ Titanium grade } \\
\hline Grade 1 & $1(1.1 \%)$ & {$[52]$} \\
\hline Grade 2 & $26(28.6 \%)$ & {$[6,12,14,26,34,35,41,42,44,50]$} \\
\hline Grade 4 & $11(12.1 \%)$ & {$[16,19,40,50,57]$} \\
\hline Grade 5 & $17(18.7 \%)$ & {$[2,18,29,37,49]$} \\
\hline Not stated & & {$[1,4,5,8,9,11,13,15,22,23,30,32,33,51,54-56]$} \\
\hline \multicolumn{3}{|l|}{ Roughness value $\left(R_{a}\right)$} \\
\hline $0-1 \mu \mathrm{m}$ & $50(54.9 \%)$ & {$[1,2,4-6,11-13,22,23,26,29,32,34,35,40,41,44,49,51,52,54-57]$} \\
\hline$>1 \mu \mathrm{m}$ & $13(14.3 \%)$ & {$[2,5,6,8,13,22,26,41,44,49,54]$} \\
\hline Not stated & $28(30.8 \%)$ & {$[9,14-16,18,19,30,33,34,37,42,44,50]$} \\
\hline
\end{tabular}


attachment. Conversely, element alloying by adding copper $(\mathrm{Cu})$ in titanium to develop Ti-Cu alloys, presented a very stable and strong anti-bacterial ability to obstruct biofilm attachment efficiently by damaging bacterial cell walls, better wear resistance, higher mechanical properties and better anti-corrosion resistance than commercially pure titanium [33]. The anti-bacterial rate was found to be greater than $90 \%$ when the Cu content in $\mathrm{Ti}-\mathrm{Cu}$ alloy was at least 3 percent by weight ( $w t \%)$ [3]. This finding is similar to another included study in this systematic review which confirmed the strong antibacterial property of Ti-3Cu alloy [56].

The titanium surfaces can also be treated with an additional layer of coating, which acts as a physical barrier against early bacterial attachment before the formation of biofilm. For example, one study focused on Avantblast ${ }^{\circ}$, a thermal treatment surface that combines an increment in the surface roughness by chemical etching with an increased thickness and crystallinity of the titanium oxide layer [50]. A different study focused on anti-bacterial bioactive glass, which is composed of silica $\left(\mathrm{SiO}_{2}\right)$, calcium $(\mathrm{Ca})$, sodium $(\mathrm{Na})$, and phosphorus $(\mathrm{P})[30]$. This forms a silica-rich hydroxyl carbonated apatite that resembles hydroxyapatite of a bone when in contact with biological fluids [30]. In another investigation, titanium oxide $\left(\mathrm{TiO}_{2}\right)$ as a coating of the titanium, was also able to produce a surface with grain size textures to allow improved osseointegration [55]. Titanium nitride (TiN), also as a coating, permitted lower bacterial biofilm compared to pure titanium coating [23].

\subsection{Comparison of titanium with other implant surface materials}

Fifteen studies compared titanium implants with other implant materials, such as zirconia and copper $(n=15$, $39.5 \%)$. Twelve studies in this systematic review compared titanium surfaces with zirconia. Zirconia is an alternative to titanium materials in implant dentistry mainly due to its esthetic properties [37]. In six studies out of thirty with beneficial effects of surface topographies (i.e. studies with significant findings in Table 1), zirconia-based implant surfaces resulted in lower bacterial counts than titaniumbased surfaces, implying that zirconia reduces the risk of peri-implantitis $[11,15,23,26,37,43]$. However, four of these studies did not disclose the $R_{a}$ values of the titanium $[15,23,37,43]$. Therefore, it was difficult to conclude whether the roughness of the surface played an important role in their investigations.

There are four other studies which found titanium to be significantly superior (i.e. less bacterial counts) than zirconia, even when their $R_{a}$ values were similar to one another $[1,12,52,57]$. Additionally, two studies did not find significant superiority between titanium and zirconia $[42,51]$. When compared to a different dental material called hydroxyapatite, only zirconia, not titanium, displayed superiority in lowering bacterial biofilm on the implant surfaces $[13,43]$. In another study, copper-based surfaces exhibited greatly decreased bacterial biofilm compared to titanium [16].

\section{Discussion}

In this review, all of the tested titanium implant surfaces permitted the formation of bacterial biofilm. However, the bacterial count, depth, morphology or viability differed between the surfaces. Thirty studies found that surface topographies have a beneficial effect on the biofilm formation and in the surface ability to allow lower biofilm attachment $(n=30,78.9 \%)$. This review did not observe one specific type of titanium surface, which was found to exhibit lower bacterial counts or biofilm mass than the other surfaces. Several studies came to the same conclusion that anodized titanium surfaces exhibited lower bacterial biofilm mass than untreated titanium surfaces $[9,18$, 55] and machined titanium had a lower bacterial biofilm than other types of implant materials (e.g. zirconia, copper) $[1,12,29]$. Polished titanium surfaces had lower bacterial biofilm than untreated titanium with rougher surfaces [4, $6,26,40,49,52]$. The differences ( $p$ value) in the comparisons between the surfaces were not consistent in all of these studies (Table 1). This implies that the superiority of a specific surface may not be concluded.

Sixty-eight percent of the titanium surfaces with beneficial surfaces (i.e. studies with significant findings in Table 1, labelled with'Yes' in the final column) had a roughness value $\left(R_{a}\right)$ of less than $1 \mu \mathrm{m}, 8 \%$ had an $R_{a}$ value of more than $1 \mu \mathrm{m}$, while $24 \%$ did not disclose the $R_{a}$ value ( $n=68 \%$, Tables 1,2$)$. In-vivo experiments confirmed that bacterial colonization starts on sites of surface roughness [5]. Conversely, there are also studies which found that surface topography did not cause any difference to the amount of microbial biofilm (i.e. studies with no significant findings in Table 1, labelled with 'No' in the final column). Eight studies found that surface topographies of the dental implants have no significant effect on the formation and attachment of biofilm $(n=8,21.1 \%)$. Only $16 \%$ of the titanium surfaces in these findings had a roughness value $\left(R_{a}\right)$ of more than $1 \mu \mathrm{m} .50 \%$ of the surfaces had an $R_{a}$ value of less than $1 \mu \mathrm{m}$, while no $R_{a}$ values were disclosed for the remaining $33.3 \%$ of the surfaces. Figure 2 shows the $R_{a}$ values of the titanium implant surfaces. The $R_{a}$ value in the studies with insignificant findings signifies that a low $\mathrm{R}_{\mathrm{a}}$ did not necessarily affect the growth of bacterial biofilm or in reducing the amount of bacterial biofilm. 


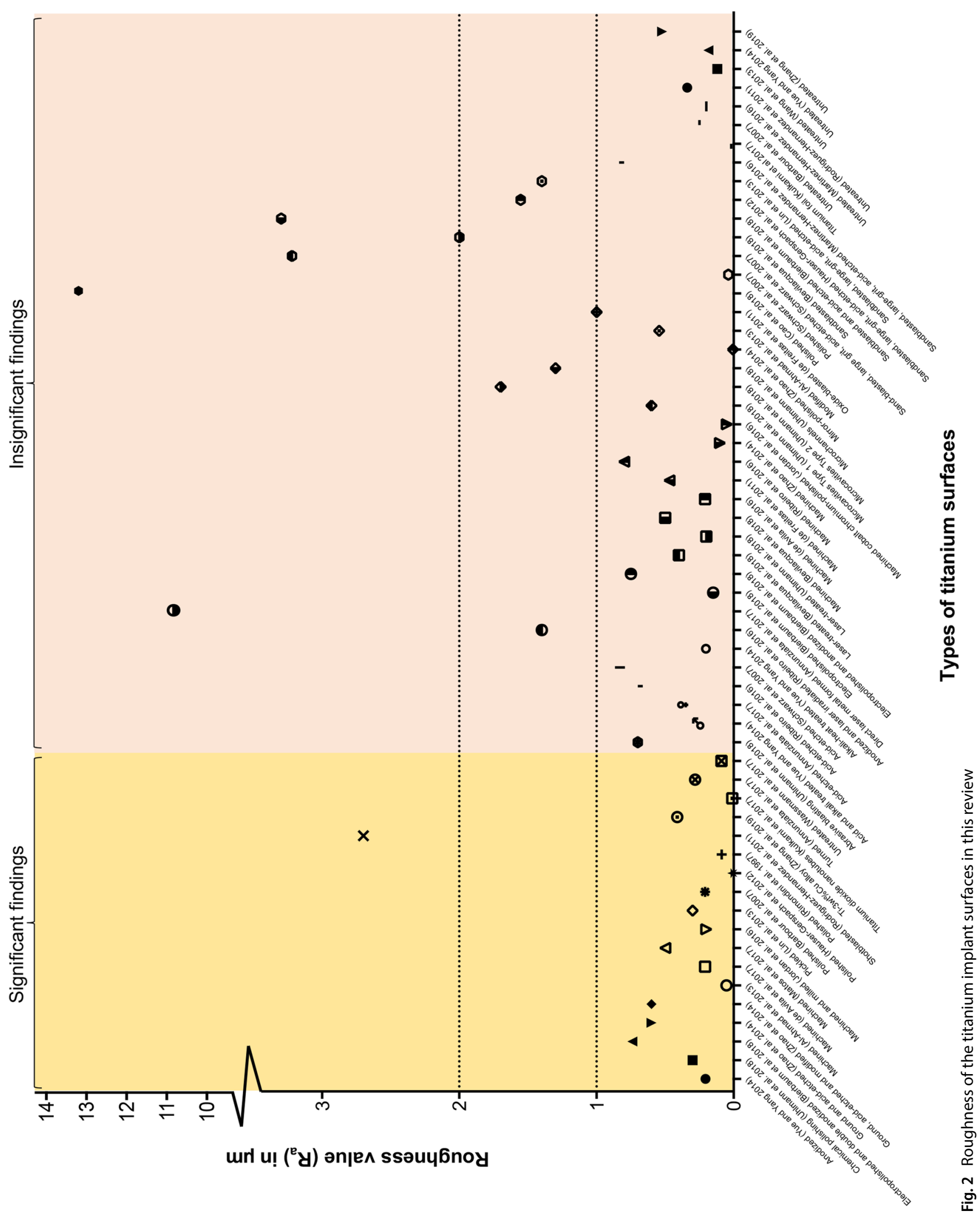


Figure 2 shows that there is no definite pattern in the $R_{a}$ values regarding surface topography and its effects on biofilm counts. $R_{a}$ values of $1 \mu \mathrm{m}$ and $2 \mu \mathrm{m}$ were indicated in Fig. 2 as these values have been considered to be a pre-requisite roughness for the long-term success of implant-supported prostheses [10]. The figure shows that a majority of the titanium surfaces had an $R_{a}$ value of $1 \mu \mathrm{m}$ in studies with both significant and non-significant findings, while a minority of the surfaces with non-significant findings had an $R_{a}$ value of $2 \mu \mathrm{m}$ (Fig. 2). These studies also suggest that surface topography was not the only important factor for biofilm accumulation. In addition, a study found that different surface treatments of the titanium implants (i.e. alkali-heat treatment and anodization) can produce two different surfaces but with approximately the same mean roughness value [55]. In another unrelated studies, 'pickled' and chemically polished titanium implants were both reported to have an $R_{a}$ value of $0.3 \mu \mathrm{m}$, regardless of their dissimilarity in the surface topography. This shows that the mean roughness is not very sensitive against specific changes in surface topography.

A certain surface topography may permit bacterial biofilm growth for a specific structure according to the pattern of roughness. Schwarz et al. [44] showed that microtopography had a highly uneven and unpredictable influence on supragingival plaque biofilm formation [44]. For example, Staphylococcus aureus growth (localizing almost completely into the surface holes) was found on laser-modified surfaces, while the biofilm covered the entire disc area as a more homogeneous layer on the sandblasted surfaces [19]. With regards to morphology, the bacterial biofilm was found to form a crater-like architecture on titanium surfaces (mimicking a honeycomb), while zirconium surfaces mimicked a complex cobweb-like structure [43]. In another study, bacterial microcolonies were more abundant along the grooves of machined discs, while in laser-treated discs, they were located within all of the holes formed by laser treatment [5]. In sand-blasted discs, they were randomly distributed on the surface [5].

The rationale for texturing the implant surfaces was to mimic the natural bone architecture, so osteoblast proliferation can be improved [27]. In this review, one study found that the micro-texturing of the titanium surfaces was also able to successfully reduce the attachment of bacteria when compared to the classical abrasive-blasted surfaces [49]. The modification of the titanium surface can increase the thickness of its oxidation layer, which can cause an interference with cell-to-cell communications in biofilm development, leading to a significant reduction in bacterial adhesion in comparison to its unmodified titanium surfaces [19]. However, regardless of the titanium's surface roughness, bacterial colonization of different implant materials was observed to be similar over time. One study focused on machined and SLA titanium surfaces and found that these surfaces were colonized by similar counts of bacteria after $24 \mathrm{~h}$ of exposure to the oral environment. Also, the different surface topographies did not significantly influence the colonizing microbiota [14]. In another investigation, the smoothing of a surface (polishing) did not reduce the ability of bacteria to adhere to metallic surfaces [29]. This is because smooth surfaces were still capable of attracting substantial levels of specific bacteria.

A number of limitations in this review need to be acknowledged. Firstly, 'turned', 'polished' or 'milled' surfaces are also called 'machined' in oral implantology and these machined surfaces are often used as a control since they serve as rougher surfaces [53]. The terminology is inconsistent in the included studies, therefore comparison of the studies could be misleading.

In twelve studies, the actual $R_{a}$ value was not reported by the authors ('not stated' in Table 1) [9, 14-16, 18, 19, 30, $33,37,42,50]$. Therefore, we could not strongly confirm the $R_{a}$ value of the surfaces which can encourage the lowest bacterial biofilm. The terms 'smooth surfaces' and 'rough surfaces' were employed to represent their differences in the surface roughness in these studies. The microbial composition has been found to differ significantly between individuals who were healthy and those diagnosed with peri-implantitis [38]. However, ten studies in our review performed their biofilm experiments using saliva which were collected from healthy individuals $[12-15,22,23,37$, $40,44,51]$. Therefore, whether their established biofilms on the implant surfaces can mimic clinically diagnosed peri-implantitis remains doubtful. Additionally, the composition and the proportion of the species that initially colonize titanium implant surfaces are influenced by the periodontal status than the surface topography of the implant [34]. One study stated that the implant surface chemical properties, surface treatment and titanium purity can also influence early bacterial colonization [50]. Actions can be taken to provoke chemical changes in the oral environment to restrict bacterial adhesion after implant placement in order to promote healing [9]. Additionally, the development of in vitro biofilm was more easily influenced by the surface features of the dental implants than biofilm formed by complex communities in the mouth [5]. This may be because of the presence of a wide range of nutrients and conditions, allowing colonization by bacteria [5]. Therefore, it is important to remember that the differences observed using in vitro experiments in the different implant surface topographies might not represent the in vivo colonization rates. Moreover, surgical techniques, soft and hard tissue characteristics, and residual precipitants (e.g. residual cement and residual floss) may also be the predisposing factors to biofilm adherence around 
dental implants [36]. Additionally, a high level of protease activity may be a predictive factor for disease progression in peri-implantitis [38]. Rougher implant surfaces were found to cause reduced treatment efficacy, for example in the treatment of biofilm by chlorhexidine, but no influence on the amount of biofilm formation [54].

\section{Conclusion}

This systematic review compared the amount of bacterial biofilm on the different surface topographies of titanium implants used in dentistry. The roughness value $\left(R_{a}\right)$ of the implants was also discussed and compared to their ability to allow low bacterial attachment and biofilm formation. An $R_{a}$ value of less than $1 \mu \mathrm{m}$ constituted the majority of the dental implant surfaces included in this review. A majority of the studies agreed that different surface topographies had an effect on reducing the bacterial biofilm growth. However, due to inconsistent significant findings, it is suggested that more experiments be performed comparing specific types of surface (e.g. polished surfaces against sand-blasted surfaces). Also, more information on the experiments (e.g. $\mathrm{R}_{\mathrm{a}}$ values) should be disclosed for a more thorough review. Additionally, existing periodontal health may be a strong predisposing factor for bacterial colonization of implant surfaces.

Acknowledgements This study is supported by the University Research Council grant under Universiti Brunei Darussalam (Grant Number: UBD/RSCH/URC/RG(b)/2018/004), led by Dr Jagjit Singh Dhaliwal (Principal Investigator).

\section{Compliance with ethical standards}

Conflict of interest The authors declare that they have no conflict of interest.

\section{References}

1. Al-Ahmad A, Wiedmann-Al-Ahmad M, Fackler A, Follo $M$, Hellwig E, Bächle M, Hannig C, Han JS, Wolkewitz M, Kohal R (2013) In vivo study of the initial bacterial adhesion on different implant materials. Arch Oral Biol 58:1139-1147. https:// doi.org/10.1016/j.archoralbio.2013.04.011

2. Annunziata M, Rizzo A, Leone C, Mangano C, Mazzola N, Nastri $L$, Papale F, Rullo F, Guida $L$ (2017) Bacterial adhesion to direct laser metal formed and mildly acid etched implant surfaces. Surf Coat Technol 328:390-397. https://doi.org/10.1016/j.surfc oat.2017.09.011

3. Bao M, Wang X, Ren J, Zhang E, Qin G, Li S, Yang L, Liu Y (2018) Optimization of mechanical properties, biocorrosion properties and antibacterial properties of wrought Ti-3Cu alloy by heat treatment. Bioact Mater 3:28-38. https://doi. org/10.1016/j.bioactmat.2018.01.004
4. Barbour ME, O'Sullivan DJ, Jenkinson HF, Jagger DC (2007) The effects of polishing methods on surface morphology, roughness and bacterial colonisation of titanium abutments. J Mater Sci Mater Med 18:1439-1447. https://doi.org/10.1007/s1085 6-007-0141-2

5. Bevilacqua L, Milan A, Del Lupo V, Maglione M, Dolzani L (2018) Biofilms developed on dental implant titanium surfaces with different roughness: comparison between in vitro and in vivo studies. Curr Microbiol 75:766-772. https://doi. org/10.1007/s00284-018-1446-8

6. Bierbaum S, Mulansky S, Bognár E, Kientzl I, Nagy P, Vrana $\mathrm{NE}$, Weszl M, Boschke E, Scharnweber D, Wolf-Brandstetter $C$ (2018) Osteogenic nanostructured titanium surfaces with antibacterial properties under conditions that mimic the dynamic situation in the oral cavity. Biomater Sci 6:1390-1402. https://doi.org/10.1039/c8bm00177d

7. Bollen CML, Papaioanno W, Van Eldere J, Schepers E, Quirynen $M$, Van Steenberghe D (1996) The influence of abutment surface roughness on plaque accumulation and peri-implant mucositis. Clin Oral Implants Res. https://doi.org/10.103 4/j.1600-0501.1996.070302.x

8. Cao Y, Su B, Chinnaraj S, Jana S, Bowen L, Charlton S, Duan P, Jakubovics NS, Chen J (2018) Nanostructured titanium surfaces exhibit recalcitrance towards Staphylococcus epidermidis biofilm formation. Sci Rep 8:1-13. https://doi. org/10.1038/s41598-018-19484-x

9. Caous JS, Lövenklev M, Fäldt J, Langton M (2013) Adhesion of streptococcus mitis and actinomyces oris in co-culture to machined and anodized titanium surfaces as affected by atmosphere and $\mathrm{pH}$. BMC Oral Health. https://doi. org/10.1186/1472-6831-13-4

10. Dank A, Aartman IHA, Wismeijer D, Tahmaseb A (2019) Effect of dental implant surface roughness in patients with a history of periodontal disease: a systematic review and meta- analysis. Int J Implant Dent 5(1):12

11. de Avila E, Avila-Campos MJ, Vergani CE, Spolidório DMP, De Assis Mollo F (2016) Structural and quantitative analysis of a mature anaerobic biofilm on different implant abutment surfaces. J Prosthet Dent 115:428-436. https://doi.org/10.1016/j. prosdent.2015.09.016

12. de Avila ED, Vergani CE, Mollo Junior FA, Junior MJ, Shi W, Lux R (2017) Effect of titanium and zirconia dental implant abutments on a cultivable polymicrobial saliva community. J Prosthet Dent 118:481-487. https://doi.org/10.1016/j.prosd ent.2017.01.010

13. De Freitas MM, Da Silva CHP, Groisman M, Vidigal GM (2011) Comparative analysis of microorganism species succession on three implant surfaces with different roughness: an in vivo study. Implant Dent 20:e14-e23. https://doi.org/10.1097/ ID.0b013e31820fb99e

14. de Melo F, do Nascimento C, Souza DO, de Albuquerque RF (2017) Identification of oral bacteria on titanium implant surfaces by $16 \mathrm{~S}$ rDNA sequencing. Clin Oral Implants Res 28:697703. https://doi.org/10.1111/clr.12865

15. Do Nascimento C, Pita MS, Santos EDS, Monesi N, Pedrazzi V, De Albuquerque Junior RF, Ribeiro RF (2016) Microbiome of titanium and zirconia dental implants abutments. Dent Mater 32:93-101. https://doi.org/10.1016/j.dental.2015.10.014

16. Doll K, Jongsthaphongpun KL, Stumpp NS, Winkel A, Stiesch M (2016) Quantifying implant-associated biofilms: comparison of microscopic, microbiologic and biochemical methods. J Microbiol Methods 130:61-68. https://doi.org/10.1016/j.mimet .2016.07.016

17. Doornewaard R, Jacquet W, Cosyn J, De Bruyn H (2018) How do peri-implant biologic parameters correspond with implant 
survival and peri-implantitis? A critical review. Clin Oral Implants Res 29:100-123. https://doi.org/10.1111/clr.13264

18. Dorkhan M, Yücel-Lindberg T, Hall J, Svensäter G, Davies JR (2014) Adherence of human oral keratinocytes and gingival fibroblasts to nano-structured titanium surfaces. BMC Oral Health 14:1-9. https://doi.org/10.1186/1472-6831-14-75

19. Drago L, Bortolin M, De Vecchi E, Agrappi S, Weinstein RL, Mattina R, Francetti L (2016) Antibiofilm activity of sandblasted and laser-modified titanium against microorganisms isolated from peri-implantitis lesions. J Chemother 28:383-389. https://doi. org/10.1080/1120009X.2016.1158489

20. Dreyer H, Grischke J, Tiede C, Eberhard J, Schweitzer A, Toikkanen SE, Glöckner S, Krause G, Stiesch M (2018) Epidemiology and risk factors of peri-implantitis: a systematic review. J Periodontal Res 53:657-681. https://doi.org/10.1111/jre.12562

21. Dutra D, Pereira G, Kantorski K, Valandro L, Zanatta F (2018) Does finishing and polishing of restorative materials affect bacterial Adhesion and biofilm formation? A systematic review. Oper Dent 43:E37-E52. https://doi.org/10.2341/17-073-L

22. Ferreira Ribeiro C, Cogo-Müller K, Franco GC, Silva-Concílio LR, Sampaio Campos M, De Mello Rode S, Claro Neves AC (2016) Initial oral biofilm formation on titanium implants with different surface treatments: an in vivo study. Arch Oral Biol 69:33-39. https://doi.org/10.1016/j.archoralbio.2016.05.006

23. Groessner-Schreiber B, Hannig M, Dück A, Griepentrog M, Wenderoth DF (2004) Do different implant surfaces exposed in the oral cavity of humans show different biofilm compositions and activities? Eur J Oral Sci 112:516-522. https://doi.org/10.111 1/j.1600-0722.2004.00171.x

24. Harwig DD, Ittiwattana W, Castner H (2001) Advances in oxygen equivalent equations for predicting the properties of titanium welds. Weld J 80:126s-136s

25. Hashim D, Cionca N, Combescure C, Mombelli A (2018) The diagnosis of peri-implantitis: a systematic review on the predictive value of bleeding on probing. Clin Oral Implants Res 29:276293. https://doi.org/10.1111/clr.13127

26. Hauser-Gerspach I, Vadaszan J, Deronjic I, Gass C, Meyer J, Dard M, Waltimo T, Stübinger S, Mauth C (2012) Influence of gaseous ozone in peri-implantitis: bactericidal efficacy and cellular response. An in vitro study using titanium and zirconia. Clin Oral Investig 16:1049-1059. https://doi.org/10.1007/s0078 4-011-0603-2

27. Iwata N, Nozaki K, Horiuchi N, Yamashita K, Tsutsumi Y, Miura $H$, Nagai A (2017) Effects of controlled micro-/nanosurfaces on osteoblast proliferation. J Biomed Mater Res, Part A 105:25892596. https://doi.org/10.1002/jbm.a.36118

28. Jemat A, Ghazali MJ, Razali M, Otsuka Y (2015) Surface modifications and their effects on titanium dental implants. Biomed Res Int 2015:1-11. https://doi.org/10.1155/2015/791725

29. Jordan RPC, Marsh L, Ayre WN, Jones Q, Parkes M, Austin B, Sloan AJ, Waddington RJ (2016) An assessment of early colonisation of implant-abutment metal surfaces by single species and cocultured bacterial periodontal pathogens. J Dent 53:64-72. https://doi.org/10.1016/j.jdent.2016.07.013

30. Karoussis IK, Kyriakidou K, Papaparaskevas J, Vrotsos IA, Simopoulou M, Kotsakis GA (2018) Osteostimulative calcium phosphosilicate biomaterials partially restore the cytocompatibility of decontaminated titanium surfaces in a peri-implantitis model. J Biomed Mater Res Part B Appl Biomater 106:26452652. https://doi.org/10.1002/jbm.b.34081

31. Kordbacheh Changi K, Finkelstein J, Papapanou PN (2019) Periimplantitis prevalence, incidence rate and risk factors: a study of electronic health records at a U.S. dental school. Clin Oral Implants Res. https://doi.org/10.1111/clr.13416

32. Kulkarni M, Junkar I, Humpolíček P, Capáková Z, Radaszkiewicz KA, Mikušová N, Pacherník J, Lehocký $M$, Iglič $A$, Hanáčková $M$,
Mozetič $\mathrm{M}$ (2017) Interaction of nanostructured $\mathrm{TiO}_{2}$ biointerfaces with stem cells and biofilm-forming bacteria. Mater Sci Eng, C 77:500-507. https://doi.org/10.1016/j.msec.2017.03.174

33. Liu R, Tang Y, Zeng L, Zhao Y, Ma Z, Sun Z, Xiang L, Ren L, Yang K (2018) In vitro and in vivo studies of anti-bacterial copper-bearing titanium alloy for dental application. Dent Mater 34:11121126. https://doi.org/10.1016/j.dental.2018.04.007

34. Martínez-Hernández $M$, Olivares-Navarrete R, Almaguer-Flores $A$ (2016) Influence of the periodontal status on the initial-biofilm formation on titanium surfaces. Clin Implant Dent Relat Res 18:174-181. https://doi.org/10.1111/cid.12251

35. Matos AO, Ricomini-Filho AP, Beline T, Ogawa ES, Costa-Oliveira $B E$, de Almeida $A B$, Nociti Junior FH, Rangel EC, da Cruz NC, Sukotjo C, Mathew MT, Barão VAR (2017) Three-species biofilm model onto plasma-treated titanium implant surface. Colloids Surf B Biointerfaces 152:354-366. https://doi.org/10.1016/j. colsurfb.2017.01.035

36. Monje A, Insua A, Wang H-L (2019) Understanding peri-implantitis as a plaque-associated and site-specific entity: on the local predisposing factors. J Clin Med 8:279. https://doi.org/10.3390/ jcm8020279

37. Nascimento C, do Pita MS, Fernandes FHNC, Pedrazzi V, de Albuquerque Junior RF, Ribeiro RF (2014) Bacterial adhesion on the titanium and zirconia abutment surfaces. Clin Oral Implants Res 25:337-343. https://doi.org/10.1111/clr.12093

38. Neilands J, Wickström C, Kinnby B, Davies JR, Hall J, Friberg B, Svensäter G (2015) Bacterial profiles and proteolytic activity in peri-implantitis versus healthy sites. Anaerobe 35:28-34. https ://doi.org/10.1016/j.anaerobe.2015.04.004

39. Pacha-Olivenza MÁ, Tejero R, Fernández-Calderón MC, Anitua E, Troya M, González-Martín ML (2019) Relevance of topographic parameters on the adhesion and proliferation of human gingival fibroblasts and oral bacterial strains. Biomed Res Int 2019:1-13. https://doi.org/10.1155/2019/8456342

40. Rimondini L, Faré S, Brambilla E, Felloni A, Consonni C, Brossa F, Carrassi A (1997) The effect of surface roughness on early in vivo plaque colonization on titanium. J Periodontol 68:556-562. https://doi.org/10.1902/jop.1997.68.6.556

41. Rodríguez-Hernández AG, Juárez A, Engel E, Gil FJ (2011) Streptococcus sanguinis adhesion on titanium rough surfaces: Effect of shot-blasting particles. J Mater Sci Mater Med 22:1913-1922. https://doi.org/10.1007/s10856-011-4366-8

42. Sánchez MC, Fernández E, Llama-Palacios A, Figuero E, Herrera D, Sanz M (2017) Response to antiseptic agents of periodontal pathogens in in vitro biofilms on titanium and zirconium surfaces. Dent Mater 33:446-453. https://doi.org/10.1016/j.denta I.2017.01.013

43. Sánchez $M C$, Llama-Palacios $A$, Fernández E, Figuero $E$, Marín MJ, León R, Blanc V, Herrera D, Sanz M (2014) An in vitro biofilm model associated to dental implants: structural and quantitative analysis of in vitro biofilm formation on different dental implant surfaces. Dent Mater 30:1161-1171. https://doi.org/10.1016/j. dental.2014.07.008

44. Schwarz F, Sculean A, Wieland M, Horn N, Nuesry E, Bube C, Becker J (2007) Effects of hydrophilicity and microtopography of titanium implant surfaces on initial supragingival plaque biofilm Formation. A pilot study. Mund- Kiefer- und Gesichtschirurgie 11:333-338. https://doi.org/10.1007/s10006-007-0079-z

45. Simon B (2018a) Process for the preparation of a topography for improved protein adherence on a body made of titanium or a titanium alloy. US 2018/0153660 A1

46. Simon B (2018b) Process for providing a defined surface topography to at least a portion of a ceramic body. US 10,040,727 B2

47. Simon B (2018c) Process for the preparation of a topography for improved blood coagulation and/or cell attachment on a body made of titanium or a titanium alloy. US 2018/0147029 A1 
48. Ting M, Craig J, Balkin BE, Suzuki JB (2018) Peri-implantitis: a comprehensive overview of systematic reviews. J Oral Implantol 44:225-247. https://doi.org/10.1563/aaid-joi-D-16-00122

49. Uhlmann E, Schweitzer L, Kieburg H, Spielvogel A, Huth-Herms $K$ (2018) The effects of laser microtexturing of biomedical grade 5 Ti-6Al-4 V dental implants (abutment) on biofilm formation. Proc CIRP 68:184-189. https://doi.org/10.1016/j.procir.2017.12.044

50. Violant D, Galofré M, Nart J, Patricio Teles R (2014) In vitro evaluation of a multispecies oral biofilm on different implant surfaces. Biomed Mater. https://doi.org/10.1088/1748-6041/9/3/035007

51. Wang M, Bai Y, Yang H, Zou H, Xia H, Wang Y (2013) Confocal laser scanning microscope evaluation of early bacterial colonization on zirconium oxide and titanium surfaces: an in vivo study. J Wuhan Univ Technol Mater Sci Ed 28:396-399. https:// doi.org/10.1007/s11595-013-0702-9

52. Wassmann T, Kreis S, Behr M, Buergers R (2017) The influence of surface texture and wettability on initial bacterial adhesion on titanium and zirconium oxide dental implants. Int J Implant Dent 3:32. https://doi.org/10.1186/s40729-017-0093-3

53. Wennerberg A, Albrektsson T (2009) Effects of titanium surface topography on bone integration: a systematic review. Clin Oral Implants Res 20:172-184. https://doi.org/10.111 1/j.1600-0501.2009.01775.x

54. Yan Lin H, Liu Y, Wismeijer D, Crielaard W, Mei Deng D (2013) Effects of oral implant surface roughness on bacterial biofilm formation and treatment efficacy. Int J Oral Maxillofac Implants 28:1226-1231. https://doi.org/10.11607/jomi.3099

55. Yue C, Yang B (2014) Bioactive titanium surfaces with the effect of inhibiting biofilm formation. J Bionic Eng 11:589-599. https ://doi.org/10.1016/S1672-6529(14)60070-6

56. Zhang Z, Zheng G, Li H, Yang L, Wang X, Qin G, Zhang E (2019) Anti-bacterium influenced corrosion effect of antibacterial Ti-3Cu alloy in Staphylococcus aureus suspension for biomedical application. Mater Sci Eng, C 94:376-384. https://doi. org/10.1016/j.msec.2018.09.057

57. Zhao B, Van Der Mei HC, Subbiahdoss G, De Vries J, RustemaAbbing M, Kuijer R, Busscher HJ, Ren Y (2014) Soft tissue integration versus early biofilm formation on different dental implant materials. Dent Mater 30:716-727. https://doi.org/10.1016/j. dental.2014.04.001

Publisher's Note Springer Nature remains neutral with regard to jurisdictional claims in published maps and institutional affiliations. 